\title{
Discurso de Eduardo Valencia-Ospina
}

\author{
Presidente de la Comisión de Derecho Internacional en su septuagésimo \\ período de sesiones
}

(Spanish original)

Me honra, en nombre de la Comisión de Derecho Internacional, dar la bienvenida a todos Ustedes a este solemne acto con el que se da inicio a la conmemoración de su 70 aniversario. Permítanme expresar nuestro agradecimiento a los dignatarios que aceptaron la invitación para hacer uso de la palabra en esta oportunidad: el S.E. Miroslav Lajčák, Presidente de la Asamblea General; el Sr. Miguel de Serpa Soares, Asesor Jurídico de Naciones Unidas; S.E. Burhan Gafoor, Representante Permanente de Singapur y Presidente de la Sexta Comisión; los representantes de los países anfitriones de la Comisión tanto en su propia Sede en Ginebra, S.E. Jürg Lauber, Representante Permanente de Suiza, como en la Sede de la Organización, la Sra. Jennifer Newstead, Asesora Jurídica del Departamento de Estado de los Estados Unidos; y el Profesor Nico Schrijver, Presidente del Instituto de Derecho Internacional.

Extiendo nuestro reconocimiento a la concurrencia que nos distingue con su presencia: Representantes Permanentes y otros miembros de Misiones Permanentes; Asesores Jurídicos de Cancillerías y de Misiones Permanentes; altos funcionarios de la Secretaría y representantes de agencias especializadas y otras organizaciones internacionales; profesores y alumnos en Facultades de Derecho y otras instituciones académicas; y antiguos miembros de la Comisión y su Secretaría.

Excepcionalmente, la Comisión de Derecho Internacional celebra en la Sede de la Organización la primera parte de uno de sus períodos regulares de sesiones, el de 2018, por marcar éste al tiempo 70 años de vida de la institución. Por decisión expresa de la Asamblea General, su órgano creador, la Comisión sesiona por cinco semanas aquí en Nueva York donde, en Lake Success, tuviera su primera session en $1949 .{ }^{1}$ De esta forma se concretiza el anhelo frecuentemente expresado en la Sexta Comisión, del cual se ha hecho eco la Comisión de Derecho Internacional, como medio conducente a fortalecer la ya estrecha relación entre los dos órganos. 1 Asamblea General de las Naciones Unidas, Resolución 72/116 (de 7 de diciembre de 2017),
para. 14. 
Dicha relación se manifiesta sobre todo en las resoluciones periódicamente adoptadas por la Asamblea General, resultado de la consideración que en cada una de sus sesiones ordinarias le da la Sexta Comisión a los informes sometidos anualmente a ella por la Comisión de Derecho Internacional. En tales informes, setenta de ellos hasta el momento, se encuentra plasmada la fundamental contribución hecha por la Comisión a lo largo de su existencia al desarrollo progresivo y la codificación del Derecho Internacional. Esos setenta informes son la major prueba de la manera constructiva y eficaz como la Comisión ha sabido desempeñar la función que le encomendara la Asamblea, en cumplimiento del mandato a ella impuesto por el Artículo 13, 1 (a) de la Carta.

La inserción de dicha disposición en el instrumento constitutivo de las Naciones Unidas no fué el resultado de una iniciativa aislada en la Conferencia de San Francisco. Por el contrario, representó un decisivo paso adelante dentro del llamado "Movimiento de Codificación", que traza sus orígenes a las postrimerías del Siglo XVIII. El "Movimiento" había recibido fuerte impulso con la fundación, en 1873, del Instituto de Derecho Internacional y la Asociación de Derecho Internacional, instituciones que, doblando en edad a la Comisión, continúan canalizando los esfuerzos privados en pro del objetivo que les es común a una y otras. Por ello adquiere especial significado que para realzar el 70 aniversario de la Comisión, haya sido el Presidente del Instituto el escogido para dictar la Conferencia Magistral con la que concluirá esta solemne jornada.

Los múltiples e influyentes resultados sustantivos a que ha llegado la Comisión de Derecho Internacional en su larga e ingente labor sobre diversos temas no requieren recapitulación en esta corta intervención. Baste con destacar que la Comisión se ha ocupado, entre otros trascendentales temas, de las tres fuentes principales del Derecho Internacional mencionadas en el Artículo 38, párrafo 1 del Estatuto de la Corte Internacional de Justicia. De ello dan fé su proyecto definitivo sobre el Derecho de los Tratados, que sirvió de base para la elaboración de la Convención de Viena de 1969. ${ }^{2}$ Este fundacional instrumento, refrendado por la casi unanimidad de los Estados Miembros, ha servido de fecunda fuente de inspiración a la Comisión de Derecho Internacional para emprender su estudio autónomo acerca de una docena de temas derivados de la Convención o estrechamente relacionados con ella. Asimismo el proyecto definitivo, a ser adoptado en el presente período de sesiones, de Conclusiones sobre la Identificación del Derecho Internacional Consuetudinario, la segunda de las Fuentes principales. Y la tercera de éstas, los Principios generales del Derecho, fué materia inscrita el año pasado en el Programa de Trabajo a Largo Plazo de la Comisión.

2 Convención de Viena sobre el Derecho de los Tratados (adoptada el 23 de mayo de 1969, entrada en vigor el 27 de enero de 1980) 1155 Serie de Tratados de Naciones Unidas 331. 
Es también apropiado resaltar aquí cuál ha sido el rendimiento de la Comisión en relación con los temas incluidos en su Programa a Largo Plazo. Desde su primer período de sesiones en 1949 la Comisión configuró un Programa de catorce temas, seleccionados de la lista de veinticinco posibles enumerados en el célebre "Memorando Lauterpacht". ${ }^{3}$ A más del de los escogidos en 1949, se ha emprendido en el curso de los años el estudio de otros 38 temas, algunos divididos en sub-temas autónomos, de los cuales están siendo considerados activamente los nueve que constituyen su agenda corriente. Exceptuando estos últimos, la Comisión ha presentado informes definitivos sobre todos los temas, salvo tres, que fueran incluidos en la lista inicial o agregados a ella. Al término de sus labores de este año, la Comisión someterá informes definitivos sobre otros dos temas, y proyectos aprobados en primera lectura en dos más. Dados los avances logrados en los demás temas de que se ocupa actualmente, la Comisión hubiera podido encontrarse al término del mandato quinquenal de sus actuales miembros en 2021, cerca de agotar su agenda corriente tal como ésta se presenta hoy en día.

Sin embargo, la Comisión continuará entretanto, desde este mismo período de sesiones, en su tarea permanente de seleccionar su temario para el futuro. En ese proceso, no deberá limitarse a temas tradicionales, como preponderamente lo ha hecho en el pasado, sino que deberá considerar también aquellos que reflejen las nuevas cuestiones surgidas en el ámbito del Derecho Internacional y las preocupaciones urgentes de la comunidad internacional en su conjunto, conforme al cuarto de los criterios adoptados en 1998 para la selección de temas. Al respecto es altamente significativo que, de conformidad con el Articulo 17 de su Estatuto, y en respuesta al llamado que hiciera en su informe del año pasado, la Comisión ha recibido de un Estado Miembro la petición formal de inscribir en su Programa de Trabajo un novedoso tema, que responde a una necesidad especialmente apremiante para el importante sector de la comunidad internacional a que ese Estado pertenece.

De lo expuesto anteriormente se deduce que la Comisión de Derecho Internacional ha cumplido con creces la noble misión que le asignara la comunidad de naciones, fielmente representada en la Asamblea General. De esa forma, su contribución ha sido fundamental para el afianzamiento del imperio del derecho en las relaciones internacionales, permitiendo su evolución después de la Segunda Guerra Mundial de un esquema de confrontación a un esquema

3 Naciones Unidas, 'Examen del derecho internacional en relación con la labor de codificación de la Comisión de Derecho Internacional: Trabajo preparatorio en el ámbito del artículo 18, párrafo 1, del Estatuto de la Comisión de Derecho Internacional' (1949) Documento de Naciones Unidas No. A/CN.4/1/Rev.1. 
de cooperación. Ha sido éste un laborioso pero constructivo proceso de multilaterización el que, sin embargo, se ve amenazado hoy en día por la invocación unilateral de parte de influyentes actores en el concierto mundial, de una desmesurada noción de "interés nacional" en el ejercicio de la soberanía.

El deber de cooperar, que explícita o implícitamente ocupa un sitio céntrico en la arquitectura de los trabajos e informes definitivos de la Comisión, es un principio bien establecido en Derecho Internacional, anclado en la Carta y en la Declaración de 1970 sobre los Principios referentes a las Relaciones de Amistad y a la Cooperación entre los Estados, ${ }^{4}$ y reflejado en multitud de otros instrumentos internacionales. Representa la concretización práctica del principio de Solidaridad el cual, como lo ha enfatizado un antiguo SecretarioGeneral, "tiene sus raíces en los principios éticos de la Carta". ${ }^{5}$ Es en la Solidaridad donde el mandato de la Comisión encuentra "telos", el fin último, como una expresión de una herencia común en un contexto global. La Solidaridad, como principio ético/jurídico internacional, da origen a un sistema de cooperación, en apoyo de la noción de que sirven mejor a la justicia y el bien común las políticas que benefician a todas las naciones.

No debe entenderse que la cooperación disminuya las prerrogativas de un Estado soberano dentro de los límites del Derecho Internacional. Por el contrario, el principio subraya el respeto de la soberanía de los Estados y su corolario, la no intervención y la función primordial de las autoridades del Estado en la adopción de medidas de toda índole que son las expresiones del "derecho de todo Estado soberano a conducir sus asuntos sin injerencias externas", como definió dicho principio la Corte Internacional en su fallo de 1986 en el caso relativo a las Actividades Militares y Paramilitares en y contra Nicaragua. ${ }^{6}$ Los principios correlativos de la soberanía y la no intervención presuponen una determinada esfera nacional o un "domain reservé", en el que un Estado puede ejercer su autoridad exclusiva. Esa autoridad soberana es un atributo esencial de la condición de Estado, pero no es absoluta en modo alguno. Como lo enfatizara el Juez Alejandro Alvarez en su Opinión disidente en el caso del Canal de Corfú, "la Soberanía confiere derechos a los Estados y les impone obligaciones." ${ }^{7}$ Y como sostuviera en un reciente artículo el antiguo miembro de

4 Asamblea General de las Naciones Unidas, Resolución 2625 (xxv) (de 24 de octubre de 1970).

5 Informe del Secretario General, 'Nuevo orden humanitario internacional: Asistencia humanitaria a la victimas de desastres naturales y situaciones de emergencia similares' (1990) Documento de Naciones Unidas No. A/45/587 para. 5 (traducción por el autor).

6 Military and Paramilitary Activities in and against Nicaragua (Nicaragua $v$ United States) (sentencia de fondo) [1986] Reportes de la CIJ 14, 106 (traducción por el autor).

7 Corfu Channel Case (United Kingdom v Albania) (opinión separada del Juez Álvarez) [1949] Reportes de la CIJ 39, 43 (traducción por el autor). 
la Comisión Martti Koskenniemi: "one is most Sovereign when one is mostly intensively engaged with the international world".

La Organización de las Naciones Unidas es ejemplo, el más perfeccionado, de cooperación internacional institucionalizada a nivel universal. Y lo es también en sí misma la Comisión de Derecho Internacional, órgano subsidiario de la Asamblea General. Dada su competencia, que abarca la amplia gama de ramas del Derecho Internacional, lo es por su composición y la forma como se procede por la Asamblea a la elección de sus miembros, que garantiza dentro de una distribución regional equitativa el cumplimiento de los criterios enunciados en el Artículo 8 del Estatuto. En este contexto es de destacar el hecho de que, a pesar de encontrarse todavía muy lejos de realización en la Comisión de Derecho Internacional el perentorio objetivo de la paridad de género en los organismos internacionales, la Comisión cuenta en el presente quinquenio con el mayor número de mujeres miembro en su historia. Y es la Comisión asimismo ejemplo de cooperación gracias a sus métodos de trabajo, diseñados para facilitar la búsqueda de bases jurídicas comunes para sus proyectos.

La Comisión ha desempeñado un papel preponderante en la construcción del edificio sobre el cual se asienta y funciona la comunidad internacional de la post-guerra. Dadas las preocupantes tendencias aislacionistas que han hecho reciente irrupción en el panorama internacional, hoy más que nunca se hace necesaria la continuada realización de su vocación en pro del afianzamiento del derecho internacional. Sigue siendo éste el baluarte más firme para asegurar la supervivencia de una sociedad internacional que todas las naciones han ayudado a construir y de la cual todas se han beneficiado.

8 Martti Koskenniemi, 'The many faces of sovereignty. Introduction to critical legal thinking' (2007) 4(2) KustafinULRev 29 o. 